
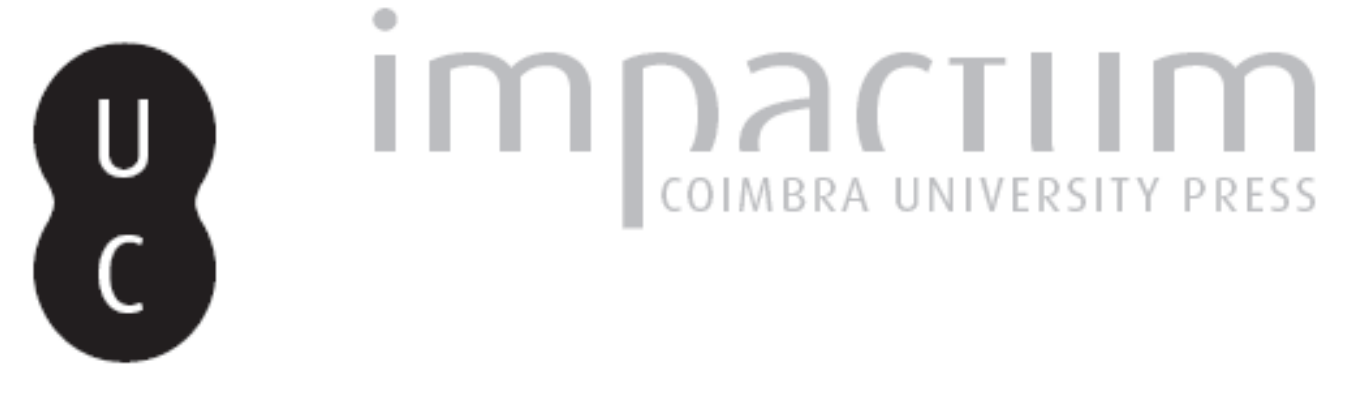

\title{
Crianças e maus tratos na familia: uma abordagem sociológica
}

Autor(es): Almeida, Ana Nunes de
Publicado por: Instituto de História Económica e Social; Imprensa da Universidade de Coimbra

URL persistente:

URI:http://hdl.handle.net/10316.2/44501

DOI:

DOI:https://doi.org/10.14195/0870-4147_37_9

Accessed : $\quad$ 26-Apr-2023 11:38:59

A navegação consulta e descarregamento dos títulos inseridos nas Bibliotecas Digitais UC Digitalis, UC Pombalina e UC Impactum, pressupõem a aceitação plena e sem reservas dos Termos e Condições de Uso destas Bibliotecas Digitais, disponíveis em https://digitalis.uc.pt/pt-pt/termos.

Conforme exposto nos referidos Termos e Condições de Uso, o descarregamento de títulos de acesso restrito requer uma licença válida de autorização devendo o utilizador aceder ao(s) documento(s) a partir de um endereço de IP da instituição detentora da supramencionada licença.

Ao utilizador é apenas permitido o descarregamento para uso pessoal, pelo que o emprego do(s) título(s) descarregado(s) para outro fim, designadamente comercial, carece de autorização do respetivo autor ou editor da obra.

Na medida em que todas as obras da UC Digitalis se encontram protegidas pelo Código do Direito de Autor e Direitos Conexos e demais legislação aplicável, toda a cópia, parcial ou total, deste documento, nos casos em que é legalmente admitida, deverá conter ou fazer-se acompanhar por este aviso.

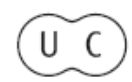




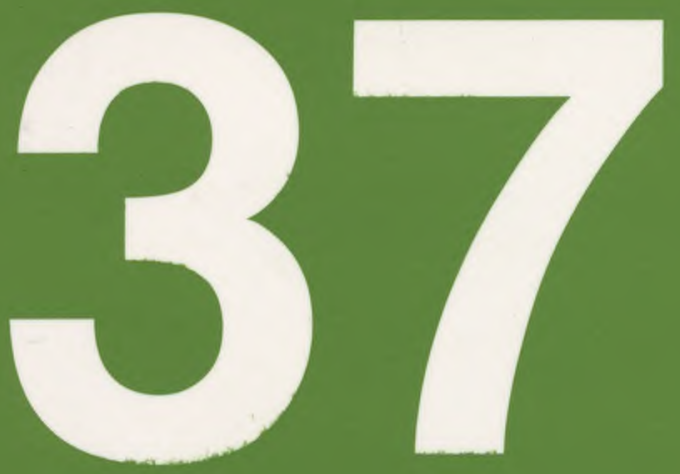

Revista Portuguesa de História

Faculdade de Letras da Universidade de Coimbra Instituto de Historia Econónica e Samial

Coimbra 05 


\section{Crianças e maus tratos na familia}

\section{- uma abordagem sociológica}

ANa Nunes de Almeida

Instituto de Ciências Sociais

Universidade de Lisboa

\section{Apresentação e objectivos}

Privilegiando uma abordagem sociológica, o artigo começa por apresentar e discutir uma das vertentes paradoxais da família moderna: a representação da infância como tempo único do investimento e cuidado afectivos contrasta com a existência de práticas brutais de abuso e negligência contra as crianças.

Não sendo um facto inédito ou sequer típico do presente, a realidade violenta de algumas infâncias impõe-se hoje (ao contrário do passado) como um problema relevante e socialmente intolerável; a sua visibilidade crescente atrai a atenção e o debate públicos. Dentro de portas, em cenário doméstico, o mau trato contra as crianças parece chocar frontalmente contra a representação hegemónica da família, entendida como concha protectora e lugar de troca de afectos, onde a infância, categoria de idade específica e vulnerável, mereceria um acolhimento particular. Ora é esta contradição que dá o mote para a construção do artigo, estruturado em quatro partes.

Num primeiro ponto, detalha-se a constelação de representações que dá forma à família (e à infância) na modernidade. A construção de uma norma dominante implica, por outro lado, o reconhecimento das suas margens e periferias, 
onde justamente emergem contextos, situações ou práticas de mau trato contra crianças - questões discutidas num segundo ponto. Dá-se conta, depois, dos principais resultados obtidos numa investigação sobre contextos socio-familiares do mau trato infantil na família, realizada em Portugal entre os anos de 1995 el999. Apresentam-se, em simultâneo, pistas de interpretação e explicação destes fenómenos de violência contra a criança. Por último, uma nota final onde se sublinha a importância das ciências sociais para a construção do mau trato como problema.

\section{Sentimento, privacidade, fusão relacional: o puzzle de valores da família moderna}

E. Durkheim definira-a já como a "família conjugal” (DURKHEIM, 1895). Por oposição à família "paternal" e "patriarcal" do passado, com a modernidade emerge uma nova forma familiar estruturada em tomo do casamento e do casal, por um lado, e onde, por outro, a qualidade intrínseca das relações entre as pessoas tomam a dianteira sobre a relação entre as coisas - bens materiais, patrimónios ou heranças. Um novo protagonismo é dado ao indivíduo, cujos interesses e sentimentos se sobrepõem claramente aos dos pais, do grupo ou do colectivo de parentesco. A ideia de que os indivíduos "servem" o interesse da instituição parece ser substituída pela sua contrária: agora é a família que deve ser um instrumento ao "serviço" da realização individual.

Burgess, Locke e Thomas, fundadores da Escola de Chicago, em meados dos anos 40 (século XX) descrevem esta evolução como a passagem de uma "família-instituição" para uma "família-companheirista". Associada a um tipo de produção agrícola e artesanal, a "família instituição", tradicional, pressupõe um conjunto de características: casamento arranjado pelos pais dos noivos; predominância de finalidades económicas (ex: transmissão de património, divisão de trabalho) como princípio de legitimação dessa união; normas autoritárias de funcionamento, com hierarquias rígidas de poder estabelecidas entre sexos e gerações; subordinação do grupo familiar às regras de conduta ditadas pelo exterior. Contrariamente, a "família companheirista", típica dos contextos modernos de "economia industrial", de mobilidade geográfica e acompanhando as intensas vagas de urbanização, assenta num princípio de afinidade inter-individual e baseia-se na livre escolha de parceiros; a sua finalidade primeira é a gratificação do indivíduo através do casamento e da procriação; a democracia, as relações de igualdade entre pais e filhos ou marido e mulher, constituem princípios básicos do seu funcionamento (BURGESS, LOCKE e THOMAS: 1960).

O tema dos valores associados à "família moderna", por contraste com os da "família tradicional" das sociedades de Antigo Regime, foi também objecto 
de estudo para historiadores. Preocupados em descrever e interpretar rupturas ou recodificações de significado associados aos comportamentos familiares na modernidade, constroem um retrato-tipo desta nova representação. Sintetizando, podemos desde logo lembrar o trabalho pioneiro de $\mathrm{Ph}$. Ariès acerca da "descoberta do sentimento da infância" (ARIÈS: 1960), um tema-chave para se perceber esta evolução. A imagem moderna da criança seria, na história do Ocidente europeu, um produto do século XVIII e de uma burguesia urbana que aprende a controlar a sua fecundidade e ostenta o "sentimento" e a "privacidade" como sinais da sua distinção.

A primazia dos afectos, do sentimento romântico no desenho do cenário familiar, a importância concedida à qualidade das relações entre as pessoas impõem-se aos interesses do parentesco, às razões instrumentais da sobrevivência ou da conservação do património familiar, à lógica institucional da ordem estabelecida. Depois, a delimitação do espaço próprio da casa, distinto do espaço público, conduz ao corte das "amarras tradicionais" que, no passado, a ligavam ao parentesco, à vizinhança ou à Igreja (SHORTER, 1977). A própria arquitectura doméstica, introduzindo o corredor e inaugurando uma especialização de divisões, abriga um novo espírito de pertença familiar e permite o isolamento individual no seio do grupo. Surge agora uma família relacional, concha de afectos, bastião da vida privada e resguardada dos olhares públicos e exteriores.

A "família sentimental" distingue-se da família tradicional do passado, "diluída" numa extensa rede de parentes, vizinhos e amigos, fortemente mobilizada em tomo da prioridade do trabalho para a sobrevivência - onde as trocas afectivas não pareciam ser verdadeiramente necessárias nem ao seu funcionamento nem ao seu equilíbrio, mas que pelo contrário ocorriam no seio de uma comunidade vizinha e envolvente, densa e calorosa.

Considerando que o micro-cosmos familiar é uma janela aberta para a macro-paisagem cultural, L. Stone descreve essa "transformação crítica" como uma passagem da "distância, deferência e patriarcalismo" para o "individualismo afectivo" (STONE: 1979). Tomando 1750 como data de referência, constata que nos sectores médio e superior da sociedade inglesa da época se começa a notar uma ligação mais intensa no interior do núcleo conjugal, em detrimento dos laços com a vizinhança e do parentesco; surge um forte sentido da autonomia individual e da liberdade pessoal na conquista da felicidade, bem como o desejo crescente de privacidade física; tende a desaparecer a tradicional associação entre prazer sexual e pecado/culpa. Esta evolução devia-se, entre outras coisas, ao declínio do parentesco e do clientelismo como princípios organizadores da sociedade, ao crescente poder do Estado e ao sucesso do protestantismo, preocupado em trazer uma "moralidade afectuosa" para dentro de casa. 
Sentimento, privacidade, fusão relacional: estes parecem ser os pilares estruturantes da nova ordem familiar emergente. A que se junta o processo de individualização, o qual de resto afecta a natureza do laço social, em sentido mais amplo (SINGLY: 2003, retomando um tema caro a E. Durkheim). No Ocidente surgem, a partir de meados do século XVIII, sociedades individualistas, centradas no indivíduo, nelas considerado a célula fundamental. São de tipo diferente das sociedades "holistas" tradicionais, referidas ao todo como princípio-base da sua organização. O mesmo sucede ao nível micro: ancorada no casal, a família é um lugar-chave da "revelação de si" e da construção da identidade individual (tanto feminina como masculina) (SINGLY: 2000).

Ora é no seio desta família sentimentalizada, privatizada, que surge uma nova representação da criança (ARIÈS: 1960). Espelho da felicidade do casal, deixa então de ser olhada como adulto em miniatura, braço para o trabalho ou instrumento da sobrevivência, sendo reconhecida como categoria de idade específica, encarada como um ser com características únicas, próprias e distintas das do adulto, na sua fragilidade e vulnerabilidade. Criança-fruto do amor dos pais, tem agora um novo espaço de socialização: a escola, lugar da aprendizagem técnica (do saber) e moral, onde é colocada junto dos seus pares e de onde se espera que saiam, um dia mais tarde, cidadãos plenos dos Estados-Nação. A família moderna é, portanto, uma "família educativa", na medida em que a aposta na socialização escolar da criança se toma uma das grandes prioridades das estratégias parentais. Aquela seria, de resto, o maior incentivo ao controlo drástico da fecundidade: ter menos filhos assegura a possibilidade de os pôr a estudar.

Neste quadro envolvente, percebem-se assim os contornos por que passa a norma da infancia moderna, aquela que hoje consideramos socialmente legítima e desejável. Neles surgem os traços de uma criança-mimo, amada pelos seus progenitores, que nela vêem encanto, doçura, ingenuidade ou inocência. Ou de uma criança-aluna, que cresce e aprende na escola, onde os seus comportamentos são pedagogicamente moralizados, disciplinados e uniformizados ${ }^{1}$. Uma criança-sujeito, que se desenvolve e progressivamente adquire a sua autonomia individual num jogo socializador entre a família e a escola. Uma criança bem-estar,

1 De facto, a representação hegemónica da família (e da infância) toma-se, ela também, um projecto de domínio político e de alisamento das diversidades sociais. Para fora (do meio burguês), são planeadas estratégias de "domesticação ao domicílio" das classes populares (esses "novos bárbaros" da sociedade industrial). Usando os dispositivos de poder e de saber do Estado Nação (FOUCAULT, 1976), visa-se inculcar-lhes a nova ordem familiar burguesa, disciplinar e moralizar costumes (FR1SCH, JOSEPH, 1977). 
a quem se asseguram formas de crescimento e desenvolvimento saudáveis. Uma criança-cidadã, protegida pelos adultos-educadores ou pelos poderes públicos nos seus direitos inalienáveis e nas suas várias formas de vulnerabilidade.

A proclamação desta nova carta de direitos tem, de resto, a sua tradução internacional mais emblemática na Convenção dos Direitos da Criança ( 1989). Defendendo "o superior interesse da criança", com carácter vinculativo para todos os países que a subscreveram, nela se estipulam princípios relativos aos direitos de protecção (do nome, identidade, pertença a uma nacionalidade, contra todas as formas de discriminação), de provisão (alimento, habitação, saúde e educação) e, no que constitui um aspecto surpreendentemente inovador, direitos também de participação, nas decisões relativas à sua própria vida e à direcção das instituições em que se integra (RENAUT: 2004; SOARES: 1998; SARMENTO e PINTO: 1997).

Construída a norma, surge simultaneamente a definição, categorização e estigmatização das suas margens. É portanto em função dela, a partir de certos valores instalados, que se reconhecem nessas margens as situações de crianças "em risco", "em sofrimento" ou "maltratadas". O que significa dizer que o "mau trato" nunca é um conceito meramente técnico ou neutro, mas uma etiqueta que se cola a um comportamento socialmente desajustado - porque viola normas prevalecentes numa dada sociedade ou práticas típicas de alguns dos seus grupos dominantes. ${ }^{3}$

\section{A família como lugar de mau trato: percursos de investigação}

É historicamente recente a visibilidade social do mau trato infantil no Ocidente, nomeadamente no seio na família. E compreende-se, afinal, que a "descoberta" da sua realidade aconteça, paradoxalmente, no contexto de um universo de valores onde o bem-estar afectivo atribuído à família e a infância gozam de uma importância inédita. A revelação da violência contra as crianças resulta da mudança dos critérios sociais de apreciação de certas relações entre os adultos e elas - tomadas inaceitáveis a partir de pontos de vista dominantes.

O papel desempenhado pela comunidade profissional dos médicos pediatras na denúncia de situações intoleráveis de abuso familiar contra as crianças foi, a este respeito, relevante. Apenas em 1939, e depois em 1946, o problema foi seriamente colocado por um radiologista, J. Caffey. Escreveu então artigos sobre "a inespecificidade e dificuldade diagnóstica dos sinais radiológicos da sífilis no esqueleto de crianças pequenas" (alguns dos quais teriam origem diferente), bem como denunciou a origem traumática da "associação de hematomas subdurais" com certas "fracturas múltiplas de ossos”. Será contudo H. Kempe, 
outro pediatra, norte-americano, que definitivamente coloca nas agendas médica e pública, a partir de 1951, a chocante questão da "síndroma da criança batida" - situação em que "crianças pequenas receberam agressões físicas graves, geralmente provocadas por pais ou seus substitutos" (CANHA: 1997). O impacto desta revelação não pára de frutificar, dentro e fora da comunidade médica, sendo até intemacionalmente equacionada a nível das organizações internacionais (ONU, UNICEF, etc). Às formas de agressão física contra a criança, vem juntar-se depois a descoberta de modalidades de privação emocional e afectiva, de negligência alimentar, da saúde ou higiene ${ }^{2}$.

A violência doméstica entra, em simultâneo, na agenda da investigação em ciências sociais. A descoberta e estudo dos contornos simbólicos da "família-refugio" moderna depara-se com a constatação, recorrente em toda a literatura especializada disponível, segundo a qual as pessoas são mais susceptíveis de serem agredidas, sexualmente vitimizadas ou mortas dentro dos seus próprios lares do que em qualquer outro lugar na nossa sociedade (DIAS: 2004). Na perspectiva da infância, aponta-se para uma outra conclusão empírica sombria: a criança pode ser maltratada em diferentes instituições e lugares, públicos e privados, mas é dentro de casa, em cenário familiar, que os maus tratos são não só mais frequentes como mais perigosos (do ponto de vista do seu desenvolvimento e crescimento). Justamente o facto de a casa se ter privatizado, e não raro constituir um bastião doméstico vedado aos olhares de fora, contribui para dificultar e vulnerabilizar a protecção pública da criança.

O percurso teórico percorrido até aqui, bem como esta última constatação de facto, legitimaram a decisão para centrar na família a realização de "um estudo sobre crianças maltratadas no País", resultante de uma encomenda da Assembleia da República feita, em 1994, ao Centro de Estudos Judiciários³ ${ }^{3}$ A esta opção metodológica juntam-se outras, que seguidamente se enunciam e em parte se explicam pela perspectiva disciplinar (genericamente, a das ciências sociais)

2 Em Portugal, o tema dos maus tratos infantis foi trazido à luz pública durante a década de 80, após a Comemoração do Ano Internacional da Criança, através do empenho explícito e concertado da comunidade pediátrica (nomeadamente da Secção de Pediatria Social da Sociedade Portuguesa de Pediatria), de magistrados (em tomo do Centro de Estudos Judiciários) e outros profissionais (trabalhando, por exemplo, na órbita do Instituto de Apoio à Criança).

3 A encomenda resultou de um largo consenso partidário no Parlamento, presidido então por Barbosa de Melo, e foi dirigida ao Centro de Estudos Judiciários, de quem Armando Leandro era então o director. Viria a ser científicamente executada no Instituto de Ciências Sociais da Universidade de Lisboa, e o Relatório final foi publicado em 2001 : A. Nunes de Almeida et. al., Famílias e Maus Tratos às Crianças em Portugal - Relatório Final. Lisboa: Assembleia da República, 2001. 
em que a equipa de investigação responsável pelo estudo se situava ${ }^{4}$. Desde logo, o destaque ao contexto envolvente destas situações de abuso e negligência.

$\mathrm{O}$ privilégio atribuído à contextualização do mau trato significa que o olhar não se dirige tanto para as características da personalidade individual dos actores que nele estão envolvidos, nem tão pouco para o sistema das dinâmicas inter-pessoais que fabricam a vida familiar, mas sobretudo para o terreno social em que o mau trato surge e que condiciona a diversidade das modalidades em que ocorre. Este não é, certamente, o único ponto de vista científico "legítimo" sobre o problema; mas a sua introdução numa área de investigação fortemente dominada pelos paradigmas das ciências médicas e da psicologia pode trazer contributos inovadores aos saberes estabelecidos.

Por outro lado, tomava-se crucial partir de uma noção abrangente de mau trato e admitir que por detrás da mesma expressão se poderiam esconder estilos e processos maltratantes de uma enorme diversidade. Assim, incluiu-se nessa noção não só as formas activas de violência contra a integridade física e psíquica da criança, como ainda as formas de privação, omissão ou negligência (material e afectiva) que comprometem o seu crescimento e desenvolvimento. A participação dos profissionais da infância na recolha de informação tomava-se, ainda, uma prioridade; procedentes de várias especialidades (saúde, educação e serviço social) e lidando, portanto, com campos e vertentes distintas da condição da infância, seriam informadores-chave sobre a realidade familiar e discreta do mau trato infantil.

Por último, estipulou-se como objectivo principal do estudo a construção de uma tipología de formas de abuso e negligência familiares contra a criança, primeiramente definidas através da consistência intema de traços directamente associados ao mau trato e, depois, pela sua cumplicidade com os contextos socio-familiares de pertença da criança. Esta opção, fortemente encorajada pela impossibilidade de realizar em Portugal um estudo de prevalência ou incidência do mau trato na população infantil ${ }^{5}$, reforçava a intenção de construir, como resultado do processo de pesquisa, uma tipología empiricamente validada - e não partir dela como axioma a priori, operação metodológica frequente (e discutível) em estudos da mesma natureza.

4 Para além da autora deste artigo (socióloga, Instituto de Ciências Sociais da Universidade de Lisboa), a equipa integrava Isabel Margarida André (geógrafa, Faculdade de Letras da Universidade de Lisboa) e Helena Nunes de Almeida (médica pediatra, Hospital Fernando da Fonseca)

5 A inexistência de bases de dados (informatizadas) sobre a população infantil sujeita a estas formas de mau trato é um poderoso handicap a tal pretensão. Embora as instituições portuguesas que intervêm no terreno possuam, em arquivo mais ou menos acessível, documentação riquíssima e detalhada sobre os casos que lhes passam pelas mãos, a sua não-sistematização ou integração num banco de dados, permanentemente alimentado e actualizado, impede esse tipo de tratamento. 


\subsection{Procedimentos e técnicas de recolha de informação, caracterização da amostra}

Apresentamos, de seguida, alguns dos principais resultados obtidos na segunda fase do estudo (realizada entre 1996-1999). Depois de uma primeira etapa, de natureza "experimental" e em que os procedimentos e instrumentos de investigação foram aplicados e testados exclusivamente na Área Metropolitana de Lisboa, abrangeu-se num segundo momento a totalidade do território nacional e todos os indivíduos nele residentes com uma idade compreendida entre os 0 e os 14 anos. A recolha de dados dirigiu-se a profissionais de infância, recrutados por via das instituições onde trabalhavam. Assim, no País foram contactados todo(a)s

- os Hospitais e centros hospitalares com urgência pediátrica

- os Centros Regionais de Segurança Social

- as Comissões de Protecção de Menores então (1995) existentes

Por outro lado, e no que respeita aos profissionais da educação, definiu-se uma estratégia alternativa. Construiu-se uma amostra de base geográfica dos estabelecimentos escolares dos 3 níveis de ensino básico, creches e jardins de infância, cujo critério se definiu a partir de uma análise estatística a nível concelhio. Aplicado à população infantil, elaborou-se um "índice de desenvolvimento humano" que fez uso de três indicadores: a taxa de mortalidade infantil, a taxa de frequência do ensino obrigatório, o índice do poder de compra das famílias. $\mathrm{O}$ índice permite sintetizar as condições de vida das crianças a partir da tripla óptica da saúde, da instrução e do rendimento familiar. Calculado o índice-resumo, os concelhos foram depois ordenados e seleccionou-se, em cada uma de 11 Regiões, a situação mais favorável, a mais desfavorável e uma intermédia - o que perfez um total de 33 concelhos, nos quais foram contactadas todas as instituições de

Quadro 1 - Amostra de concelhos para a aplicação do inquérito às instituições de educação

\begin{tabular}{|l|c|c|c|}
\hline \multicolumn{1}{|c|}{ REGIÃO } & Situação + favorável & Situação intermédia & Situação - favorável \\
\hline NORTE LITORAL & Viana do Castelo & Vila Nova Famalicão & Lousada \\
\hline NORTE INTERIOR & Vila Real & Torre de Moncorvo & Valpaços \\
\hline A METROP PORTO & Maia & Vila Nova de Gaia & Vila do Conde \\
\hline CENTRO LITORAL & Marinha Grande & Anadia & Montemor-o-Velho \\
\hline CENTRO INTERIOR & Lousã & Fundão & Sátão \\
\hline OESTE/RIBATEJO & Alenquer & Cartaxo & Ferreira do Zêzere \\
\hline A METROP LISBOA & Almada & Loures & Amadora \\
\hline ALENTEJO & Évora & Ponte de Sôr & Portei \\
\hline ALGARVE & Albufeira & Faro & Olhão \\
\hline AÇORES & Vila do Porto & Vila Praia da Vitória & Ribeira Grande \\
\hline MADEIRA & Funchal & Ponta do Sol & Santana \\
\hline
\end{tabular}


ensino públicas (do $\mathrm{I}^{\circ}$ ao $3^{\circ}$ ciclos), creches e jardins de infância, IPSS com valências dirigidas à infância (995 instituições no total).

Quanto ao processo de inquirição, foi construído um inquérito por questionário, administrado por via postal, e organizado em tomo de 4 grandes tópicos: o grupo doméstico da criança; o crescimento e desenvolvimento da criança; o mau trato (tópico que incluía uma descrição livre do episódio de abuso ou negligência); o(s) agressor(es).

Depois de uma primeira etapa de codifícação/recodificação de respostas, passou-se à construção de uma base de dados onde foi introduzida toda a informação obtida no inquérito. O tratamento estatístico da informação incluiu dois tipos de análise: o apuramento das frequências obtidas nas várias modalidades de resposta das diversas questões que configuravam o questionário; a construção de uma tipología de maus tratos contra a criança na família.

É interessante constatarmos, desde logo, o nível tão desigual de respostas institucionais ao pedido do ICS, aliás reforçada por uma carta assinada pelo Director do CEJ: os $86 \%$ dos Centros Regionais de Segurança Social ou os $69 \%$ dos hospitais contrastam com os $11 \%$ das IPSS, os $3 \%$ das escolas/jardins de infância ou, mesmo (tendo em conta as atribuições e funções) os $37 \%$ das então designadas Comissões de Protecções de Menores.

Quadro 2 - A recolha de informação - resultados

\begin{tabular}{|l|c|c|c|c|c|c|}
\hline & \multicolumn{3}{|c|}{ INSTITUIÇÕES } & \multicolumn{3}{c|}{ QUESTIONÁRIOS } \\
\cline { 2 - 7 } & contactadas & responderam & $\%$ & enviados & recebidos & $\%$ \\
\hline Hospitais & 42 & 29 & 69,0 & 490 & 299 & 61,0 \\
\hline Centros Reg. Seg. Social & 22 & 19 & 86,4 & 220 & 199 & 90,5 \\
\hline Comissões Prot. Menores & 67 & 25 & 37,3 & 335 & 132 & 39,4 \\
\hline Escolas, jardins infancia & 780 & 24 & 3,1 & 2340 & 69 & 2,9 \\
\hline IPSS - valência infância & 215 & 24 & 11,2 & 555 & 56 & 10,1 \\
\hline Total & 1126 & 121 & 10,7 & 3940 & 755 & 19,2 \\
\hline
\end{tabular}

Fonte: Inquérito aos Maus Tratos às Crianças em Portugal, ICS-UL, 1996.

E o que dizer, no geral, dos contornos desta amostra, qualitativamente construída pelos profissionais da infância, composta por 755 casos de crianças vítimas de mau trato (abuso e negligência) na família ? Impõe-se, a este respeito, uma nota metodológica. Sendo o mau trato uma construção social, é bom não esquecermos que estes resultados sinalizam, em primeira linha, representações dominantes no interior de universos profissionais distintos, isto é, dão-nos sobretudo um diagnóstico da sua visibilidade no quadro de olhares socialmente situados - mais do que reflectem a sua realidade e presença efectivas no terreno. 
Os resultados obtidos revelam, entre outras coisas, a forte incidência na amostra de população residente em contextos habitacionais muito degradados (mais de 37\% das famílias reside em "barraca", "parte de casa" ou "quarto"). Este cenário desfavorecido reencontra-se nos níveis de instrução e leque de profissões dos adultos responsáveis pela criança-vítima $-19 \%$ sem qualquer grau de ensino, $37 \%$ apenas com o ensino primário; predomínio de profissões femininas e masculinas manuais, pouco qualificadas, mal remuneradas; forte presença de inactivos ("domésticas", reformados, desempregados). A facilidade de exposição dos quotidianos familiares das classes populares ao olhar dos outros, até pelo uso que aquelas fazem dos serviços públicos (de educação e saúde, nomeadamente) - em contraste com o resguardo privado que protege os comportamentos familiares das classes favorecidas - explicará em parte o seu predomínio na amostra. Contudo, tal focagem não nos deve fazer esquecer que os adultos responsáveis pela criança distribuem-se por todos os níveis de escolaridade (desde o ensino superior à ausência completa de competências escolares).

Comparativamente aos dados nacionais sobre a estrutura dos agregados domésticos em Portugal, nota-se um peso claramente excessivo dos arranjos de tipo "monoparental" (25\% na amostra, 8,5\% no País na década de 90$)$ - não esquecendo, contudo, que a maior parte das crianças maltratadas da amostra (42\%) reside em "famílias nucleares", evidenciando que o arranjo composto exclusivamente por pais e filhos biológicos é largamente predominante. Sublinhe-se, por outro lado, o facto de a monoparentalidade constituir mais facilmente, pela sua menor presença estatística na população portuguesa, um alvo para os olhares vigilantes da comunidade e, por isso, ser mais facilmente assinalada como contexto de risco para a criança.

Em 10\% das famílias de pertença da criança reside um indivíduo portador de doença crónica; em $7 \%$ delas um indivíduo com deficiência física e em $25 \%$ um indivíduo portador de doença mental; $16 \%$ das famílias com quem reside a criança maltratada possui indivíduos toxicodependentes. $\mathrm{O}$ alcoolismo assume uma expressão impressionante na amostra e acentua a vertente pré-modema da constelação de mau tratos: metade $(50 \%$ !) das crianças reside em grupos domésticos onde um, pelo menos, dos seus membros é classificado como alcoólico.

Constata-se, ainda, uma elevada expressão numérica das situações de instabilidade conjugal dos pais biológicos da criança. Em mais de metade dos casos, o laço foi ou está a ser quebrado (33\%), ou mesmo nunca chegou a existir (12\%). Para além da extrema vulnerabilidade e curta duração deste vínculo, em cerca de metade dos casais reconhecem-se sinais evidentes de "violência conjugal". É um indicador que chama a atenção para a natureza doméstica e familiar da violência que se pratica contra as crianças. Esta não é, muitas vezes, 
um acto isolado, mas um comportamento cujo significado se compreende em função do todo em que se insere.

$\mathrm{Na}$ amostra regista-se, por outro lado, um equilíbrio numérico entre rapazes e raparigas e uma dispersão dos maus tratos por todos os grupos etários de crianças. A grande maioria tem irmãos, contando-se apenas $16 \%$ de filhos únicos, sendo que o peso das fratrías de 2 ou mais irmãos é mais expressivo do que na população residente. Há uma incidência expressiva dos "filhos mais novos". Apesar de a idade da mãe ao nascimento do filho se situar maioritariamente no grupo dos 20-29 anos, é muito alta a percentagem de mães adolescentes (13\% tiveram o filho até aos 19 anos).

A relação destas crianças com a escola é precária. Cerca de $1 / 3$ falta sistematicamente às aulas, 1/4 chega regularmente atrasada, 1/3 repetiu pelo menos um nível de ensino. Uma impressionante quantidade de crianças permanece sozinha em casa (45\%), sem a guarda de um adulto responsável e por períodos longos de tempo. Apenas 1/4 delas faz uma vigilância médica regular e $20 \%$ não possui o boletim de vacinas em dia. Cerca de $11 \%$ das crianças é portadora de doença crónica, $8 \%$ possui alguma deficiência física e 10\% doença mental. São números que apontam para o facto de o nascimento de um bebé portador de alguma deficiência ou de doença permanente surgir, desde logo, como situação potenciadora de riscos, na medida em que as sobrecargas inerentes a qualquer uma dessas situações são dificilmente suportáveis por grupos mais desfavorecidos.

Quanto aos agressores, eles residem, quase sempre, com a criança e pertencem ao seu agregado familiar mais próximo. São na esmagadora maioria dos casos os seus progenitores, já que o pai biológico, a mãe ou ambos estão directamente envolvidos em cerca de $65 \%$ destas situações de mau trato. Pelo contrário, as figuras da madrasta e do padrasto esbatem-se quase totalmente no universo de agressores ou negligentes. Em cada 100,45 são considerados "alcoólicos" pelos profissionais (ficando a toxicodependência a uma grande distância deste resultado). Encontramos muitos deles, ainda, marcados por alguma deficiência mental (16\%).

\subsection{Uma tipología de formas de abuso e negligência}

A construção de uma tipología de maus tratos às crianças na família, resultante do tratamento da informação empírica expressamente recolhida para esse efeito através de inquérito por questionário, constituía o principal objectivo do estudo. Apresentam-se de seguida e caracterizam-se sistematicamente, nos seus traços mais salientes, os nove tipos obtidos ${ }^{6}$ através da inquirição. Cada um deles é,

6 Os tipos foram primeiramente caracterizados a partir de traços associados à sua especificidade interna (as chamadas “variáveis activas”): modalidades de mau trato que ocorrem; modalidades 
grosso modo, uma síntese de características máximas, apontadas pela sob ou sub-representação das modalidades de um extenso leque de variáveis.

Tipo 1 - Abuso emocional com agressão física

- Modalidades que ocorrem: abuso emocional (criança insultada, ameaçada, acusada, objecto de chantagem, espectadora de cenas de extrema violência - designadamente conjugal - durante as quais vem a ser fisicamente agredida); agressão física. Modalidades que não ocorrem: abandono temporário, falta de afecto, falta de vigilância médica, falta de higiene, abuso sexual, abandono por períodos longos em casa. O mau trato deixa lesão na face. E relatado pela mãe ou pelo pai.

- Família residente na Área Metropolitana de Lisboa, Algarve ou Açores. Contexto residencial de qualidade média/baixa. Pais em processo de separação. Família recomposta materna. Madrasta ou "outro familiar" é o adulto responsável pela criança. Adultos responsáveis pela criança com níveis de instrução altos (secundário/superior), profissões como técnico superior ou médio, empregado do comércio e dos serviços, operário da indústria.

- A criança é do sexo masculino, com idade superior a 2 anos, filho único ou filho mais velho; faz vigilância de saúde.

- As figuras da mãe e do pai destacam-se entre os agressores; agressor toxicodependente ou alcoólico.

Tipo 2 - Agressão física com sequelas

- Modalidades que ocorrem: agressão física muito violenta (criança abanada, queimada, atirada, espancada, mordida, pisada, asfixiada, etc.). Modalidades que não ocorrem: falta de higiene. O mau trato deixa todo o tipo de lesões no corpo da criança, com excepção dos órgãos genitais, e deixa sequelas físicas. Relatado pela criança.

- Família residente na Madeira, em contexto residencial degradado. Família recomposta paterna. Adultos responsáveis pela criança com graus de instrução médio e baixo.

- A criança é do sexo masculino, com idade entre os 2 e os 5 anos; não faz vigilância de saúde, é vítima de insucesso escolar, já praticou actos qualificados como crime.

de mau trato que não ocorrem; lesões resultantes; sequelas a médio ou a longo prazo. As 25 modalidades de mau trato (recobrindo uma vasta gama de formas de abuso e negligência) foram obtidas a partir da descrição livre feita pelo profissional que preencheu o inquérito.

Para mais pormenores técnicos relativos à construção da tipologia, consultar ALMEIDA, A. Nunes de, ANDRÉ, I. e ALMEIDA, H. Nunes de, (2001), Famílias e maus tratos às crianças em Portugal, Lisboa: Assembleia da República, 2001. 
- Entre os agressores destacam-se o pai, a mãe, o "pai e outros", os portadores de deficiência física, os toxicodependentes e os alcoólicos.

\section{Tipo 3 - Intoxicação}

- Modalidades que ocorrem: intoxicação intencional da criança com substâncias nocivas como o álcool, sedativos, doses excessivas de calmantes. Deixa sequelas psíquicas.

- Região de residência: Centro Interior, Norte Interior. Contexto residencial de qualidade média. Família alargada. Grau de instrução médio/baixo dos adultos responsáveis pela criança.

- A criança é do sexo feminino, maior de 4 anos; não faz vigilância de saúde; é portadora de doença mental; alcoólica; falta à escola; chega atrasada às aulas; vítima de insucesso escolar; deixada só, em casa; já praticou actos qualificados como crime.

- Pai, mãe ou ambos são os agressores; portadores de deficiência física, deficiência mental; toxicodependentes.

\section{Tipo 4 - Abuso sexual}

- Modalidades que ocorrem: abuso sexual (violação hetero ou homossexual, violação com objectos). Modalidades que não ocorrem: abandono temporário, exposição a cenas de violência, falta de afecto, alimentação inadequada, falta de vigilância médica, falta de higiene. O abuso é portanto praticado em cenários de "aparente" bem-estar material e afectivo da família. Deixa lesão nos órgãos genitais e sequelas psíquicas na criança.

- Região de residência: Algarve, Alentejo, Área Metropolitana de Lisboa, e Madeira (padrão de distribuição meridional). Pais em processo de separação. Contexto residencial de qualidade média/baixa. Família recomposta materna (presença do padrasto no contexto da residência). Graus de instrução médio/baixo dos adultos responsáveis pela criança.

- A criança é do sexo feminino, tem uma idade entre os 10-14 anos, ou 4-9 anos. Faz vigilância de saúde.

- O agressor é, para além do pai, "outro familiar", "outro não familiar". Não co-residente.

\section{Tipo 5 - Trabalho abusivo}

- Modalidades que ocorrem: absentismo escolar (criança falta à escola, chega atrasada às aulas, repete anos escolares), mendicidade (criança vagabundeia pelas ruas, pede em semáforos, arruma carros, realiza pequenos furtos). Sobrecargas de trabalho doméstico. 
- Região de residência: Norte Interior, Oeste/Ribatejo, Açores, Madeira. Áreas rurais do país. Contexto residencial degradado. Família monoparental. Mãe é um dos adultos responsáveis pela criança. Grau de instrução dos adultos responsáveis pela criança baixo ou nulo.

- A criança é do sexo masculino, tem uma idade entre os 6 e os 14 anos. $\mathrm{Na}$ fratría é um irmão do meio. Não faz vigilância de saúde, falta à escola, chega atrasada às aulas, vítima de insucesso escolar.

- O agressor é portador de deficiência mental; alcoólico.

Tipo 6-Ausência de cuidados básicos

- Modalidades que ocorrem: alimentação inadequada (criança vítima de fome, malnutrição, não faz dieta alimentar aconselhada, etc); falta de higiene (criança com piolhos, mordida por pulgas, não sabe utilizar casa de banho); falta de vigilância médica (não tem boletim de vacinas em dia, é impedida de ser internada em hospital para tratamento médico), falta de afecto (rejeição afectiva da criança, falta de atenção e disponibilidade dos pais). Modalidades que não ocorrem: abuso sexual, agressão física. Não existem lesões. Relatado por técnicos do serviço social e outros técnicos.

- Região de residência: Oeste/Ribatejo, Norte Litoral, Alentejo e Açores. Contexto residencial degradado. Família alargada com avós. Grau de instrução baixo/nulo dos adultos responsáveis pela criança. Adulto responsável pela criança desempregado ou com profissão ilícita (como prostituta, proxeneta, vendedor de droga).

- Criança do sexo masculino, com idade inferior a 4 anos; não faz vigilância de saúde. Sobre-representação de crianças deficientes ou portadoras de doença crónica; alcoólicas.

- Os agressores são o pai e a mãe; portador de deficiência física; portador de deficiência mental; alcoólico.

\section{Tipo 7-Ausência de Guarda}

- Modalidades que ocorrem: abandono temporário da criança (deixada só em casa, à guarda de irmãos menores ou alguém incompetente para tomar conta dela-deficiente, idoso, etc.), alimentação inadequada. Modalidades que não ocorrem: abuso sexual, agressão física. Mau trato relatado por técnicos do serviço social.

- Família residente na Área Metropolitana do Porto, no Alentejo. Contexto residencial de qualidade média. Os pais nunca viveram juntos. Família monoparental materna. Grau de instrução dos adultos responsáveis pela criança: baixo, médio, superior. Adultos responsáveis pela criança reformados ou com profissões ilícitas. 
- A criança é do sexo feminino, recém-nascida ou com idade inferior a 6 anos. Não faz vigilância de saúde. Portadora de doença crónica. Deixada, só, em casa.

- Agressor: mãe, mãe e pai; portador de deficiência física, deficiência mental; toxicodependente.

\section{Tipo 8 - Abandono definitivo}

- Modalidades que ocorrem: abandono definitivo (criança abandonada ao nascimento na maternidade, em vão de escada, na rua, num colégio, etc); falta de hábitos de sono. Modalidades que não ocorrem: abandono temporário, agressão física. Relatado por vários técnicos da infância, serviço social e saúde.

- Região de residência: Centro Litoral

- A criança é do sexo masculino, recém-nascida

- O agressor é portador de deficiência física, toxicodependente.

Tipo 9 - Mau trato in utero

- Modalidades que ocorrem: mau trato in utero (mãe batida durante a gravidez - nascimento prematuro; vítima do contágio de sida, fetopatia alcoólica, síndroma de privação, sífilis, parto no domicílio - tétano neonatal, etc), falta de afecto. Modalidades que não ocorrem: agressão física. O mau trato deixa sequelas neurológicas. Relatado pelos técnicos de saúde.

- Região de residência da família: Área Metropolitana de Lisboa. Contexto residencial degradado. Família alargada com avós. Grau de instrução dos adultos responsáveis pela criança: nível médio.

- A criança é do sexo masculino, recém-nascida ou com idade inferior a 1 ano; na fratria é o irmão mais novo. Não faz vigilância de saúde.

- Agressor: mãe, pai e outros; toxicodependente; alcoólico.

O desenho desta galeria de retratos revela, desde logo, a extrema diversidade e perigosidade dos maus tratos infantis em casa. Através dela emerge a sombria e trágica realidade de muitas infâncias que não encontram, na família, o lugar da gratificação afectiva ou o do cuidado protector que lhes confere a modernidade. As formas de abuso e de negligência de que as crianças são vítimas não constituem, por outro lado, uma paisagem plana ou regular: cada tipo de mau trato tem não só características internas próprias que o distinguem dos restantes, como ainda essa diversidade não se organiza socialmente ao acaso. Variáveis externas, isto é, relativas ao contexto envolvente onde acontecem as formas de abuso e negligência (por exemplo a composição e forma do grupo doméstico onde reside a criança, a sua posição na estrutura social), constituem também dimensões características e distintivas de um tipo de mau trato, relativamente a outro. Disso nos ocuparemos nos pontos seguintes. 


\subsection{Maus tratos: sinais e sentidos da diversidade}

O contexto familiar de pertença da criança constitui, desde logo, um poderoso diferenciador. Do ponto de vista da sua composição e estrutura, e se bem que as famílias simples (pais e filhos biológicos) predominem na amostra, o peso das famílias não-nucleares (quer monoparentais, como recompostas) é substancialmente "excessivo" (tendo em conta os valores nacionais). Não se joga aqui, provavelmente, um poder explicativo da "forma", em abstracto ou em si própria, destes arranjos. A questão prende-se sobretudo com os processos de ruptura conjugal ou recasamento que lhes dão origem, através dos quais não raro se reflecte negativamente na criança ora o conflito da separação dos pais, ora a quebra de convívio com as pessoas que lhe eram afectivamente significativas, ora ainda a entrada em cena dos novos companheiros conjugais dos seus progenitores. Efectivamente, e no que constitui um sinal da turbulência que pode encrispar estes processos, encontra-se uma sobre-representação das famílias recompostas nas situações de "abuso emocional" e "agressão física" (caso das recompostas paternas) ou do "abuso sexual" (caso das recompostas maternas, onde entra em cena a figura do padrasto-abusador).

As famílias monoparentais surgem, por seu tumo, com um destaque particular nas grandes negligências relativas a cuidados básicos da saúde, educação, alimentação ou higiene, no que constitui um sinal da sua fortíssima vulnerabilidade a situações de pobreza e privação material ${ }^{7}$. Encontramo-las sobre-representadas, ainda, nas formas de trabalho abusivo e ausência de guarda - destaque que nos remete para a vulnerável rede social de apoio, formal e informal, que no quotidiano rodeia estas famílias e tão dificilmente ampara a guarda das suas crianças.

A existência de sinais de violência na relação conjugal surge como uma outra variável contextual a marcar diferença e especificidade - de certos tipos de mau trato, relativamente a outros. Sinaliza a importância de se ter em conta o funcionamento do todo (familiar) para compreender a parte (a relação violenta com a criança). As relações hierárquicas e estatutárias entre sexos e gerações, a representação masculina e autoritária do poder em casa davam forma à representação tradicional da família; e legitimavam, ou pelo menos de certa forma desculpavam, os comportamentos violentos do marido-pai, contra a mulher-esposa e a criança-filho. Ao modelo do passado junta-se hoje, porém, uma outra representação do casal e da família, da qual não estão excluídos cenários propícios à emergência de comportamentos violentos.

${ }^{7}$ Facto que a investigação tem vindo sobejamente a comprovar - veja-se, por exemplo, K. Wall e C. Lobo (1999) "Famílias monoparentais em Portugal”, Análise Social, 34 (150), pp. 123-145. 
O casal privatizado e sentimentalizado traduz-se numa crescente margem de autonomia dos parceiros para construírem, à sua própria medida, regras de partilha de rotinas, tarefas e poderes (mais ou menos fusionais ou simétricos), modalidades e tempos de abertura ao exterior (mais ou menos extensas), formas de regulação (mais ou menos contratuais). Novas tensões surgem, porém, neste casal-companheirista responsável pelo fabrico do seu próprio estilo conjugal, as quais podem transbordar e perturbar a relação parental. Tensão entre ideais de fusão e individualismo, por exemplo: os cônjuges devem na família partilhar tudo numa comunidade total ou, pelo contrário, realizar através da família o seu eu-individual? Tensão, ainda, entre o apelo à mudança, o imperativo de inovação (a norma que hoje se identifica com o progresso) e uma outra representação da família como refugio, âncora fixa nesse universo em permanente mobilidade (desqualificada pela impressão de fechamento e rotina) (KELLERHALS, WIDMER e LEVY: 2004). Aos focos de tensão, potenciadores de violência, junta-se o fechamento desta concha afectiva no espaço da casa, bastião da vida privada: a família pode tomar-se num ghetto-prisão, terreno de risco onde tensões e contradições se armazenam, acumulam e vêm a explodir. Não raro contra as crianças.

A existência de violência entre os pais surge, assim, fortemente associada à "agressão física", ao "abuso emocional com agressão" (nomeadamente em caso de separação litigiosa), à "intoxicação" e, ainda, a formas de "trabalho abusivo". Já o caso do "abuso sexual" se destaca aqui pela negativa, na medida em que não lhe surgem acoplados quaisquer traços de violência (conjugal ou parental); a agressão deixa quase sempre lesão genital, mas a ausência de outras marcas no corpo da criança sugere a perversa cumplicidade entre o agressor e a sua jovem vítima, que aparentemente lhe cede e "entra no jogo" sem oferecer resistência.

A existência e composição "do grupo de irmãos" condicionam também formas de mau trato. A ordem da criança na fratria associa-se significativamente a diferentes tipos de abuso e negligência. Assim, o filho mais velho ou o filho único surgem tipicamente associados aos grandes "abusos emocionais" ou às "agressões físicas" em geral ("abuso sexual” incluído). Estreando com o seu nascimento os papéis e competências parentais, é através do seu crescimento que os pais confrontam as suas primeiras expectativas e modelos de criança com uma realidade infantil que nem sempre neles encaixa. Ora, em sociedades drasticamente envelhecidas como a portuguesa ${ }^{8}$, onde os jovens têm cada vez

80 total de crianças (0-14 anos) na população residente portuguesa baixou de cerca de 2 milhões e quinhentos indivíduos em 1981 para 1 milhão e 900 mil (em 1991) e 1 milhão e 600 mil (2001). A queda de efectivos é portanto especialmente vincada na década de 80 (com uma variação negativa a rondar os 20\%) - (ALMEIDA e ANDRÉ: 2004) 
menos a oportunidade de observar ou treinar-se no cuidado de bebés e crianças (irmãos, primos, por exemplo), o primeiro filho do casal é, muitas vezes, a primeira criança com que pai e mãe se relacionam. Esta impreparação para a parentalidade constitui, sem dúvida, um factor de risco em matéria de mau trato infantil.

Já o filho mais novo (e sobretudo o que pertence a uma fratria numerosa) é uma vítima típica das grandes negligências de "cuidados básicos" ou de "guarda", ou ainda do "mau trato in utero". Esta sobrerrepresentação pode dever-se a um mero critério de escolha, utilizado pelo técnico que responde ao inquérito: dentro de uma fratria, seleccionou para caso de estudo a criança que mais recentemente ilustra um mau trato estrutural naquela família, o qual porém teria afectado as restantes. Mas, por outro lado, o filho mais novo (menos desejado? não planeado?) pode ter vindo sobrecarregar um quotidiano e sobrevivência familiares apertados e ser o seu peso excessivo o factor na origem destas formas graves de negligência.

Apesar de os grupos sócio-profissionais desfavorecidos terem uma presença mais expressiva na amostra do estudo, verificámos que os maus tratos, na sua dupla vertente de abuso e negligência, afectam crianças e famílias pertencentes a todos os meios sociais e não só aqueles. Não as afectam, contudo, da mesma maneira. Desde logo, é importante sublinharmos a maior dificuldade metodológica em captar o mau trato praticado em famílias pertencentes a meios económica e culturalmente favorecidos, o que evidentemente e à partida contribui para uma sua presença mais tímida na amostra. A preservação que fazem dos seus quotidianos domésticos, os espaços resguardados e de acesso selectivo em que circulam os seus filhos no decurso do sua socialização, protegem-nas mais eficazmente dos olhares vigilantes e moralizadores vindos de fora, designadamente por parte dos técnicos dos serviços públicos educativos, de saúde ou de segurança social. Ainda que discreta, a presença de franjas das classes superiores na amostra permite avançar algumas conclusões no que toca a diversidade introduzida pela origem ou pertença social no desenho do cenário do mau trato.

O lugar que a família da criança ocupa no espaço social introduz variações significativas nas modalidades de mau trato que sobre ela recaem. A este respeito, e curiosamente, apenas a "ausência de guarda" surge como uma excepção, isto é: os casos em que a criança é deixada sozinha em casa ou ao cuidado de irmãos menores revelam-se situações independentes do nível de instrução dos adultos responsáveis por ela, da sua profissão mais ou menos qualificada. $O$ facto de acontecer indistintamente em todos esses grupos mostra como a questão da guarda da criança e o problema da conciliação entre papéis familiares e profissionais (para homens e mulheres), num país que possui das mais altas taxas de 
actividade feminina a full time na União Europeia ${ }^{9}$, dos mais longos horários de trabalho e simultaneamente modelos muito assimétricos de divisão sexual das tarefas domésticas (TORRES e SILVA: 1998), são transversais aos diferentes meios sociais e constitui uma relação ainda longe de estar resolvida. O caso das crianças portadoras de alguma deficiência ou doença crónica, tão frequentemente sobrerrepresentadas nestes casos de "ausência de guarda" revela aliás, de forma extrema, a debilidade e insuficiência dos serviços de apoio à família e parentalidade.

Já os outros tipos de mau trato apresentam uma variação diferencial por meios sociais de pertença da família da criança. As "formas de trabalho abusivo" (dentro ou fora de casa), as "grandes negligências da saúde, alimentação e de higiene" aparecem fortemente associadas a grupos em situação de pobreza ${ }^{10}$, a bolsas de exclusão ou mesmo de marginalidade - sinalizados pela presença de contextos residenciais degradados, franjas de invidíduos analfabetos ou com baixíssimos níveis de escolaridade, profissões femininas e masculinas desqualificadas na agricultura (trabalhador agrícola), na indústria (operário da construção civil) ou serviços (pessoais e domésticos), por índices de inactividade (doméstica, reformado ou desempregado) e actividades económicas ilícitas (venda de droga, prostituição). Em certo sentido, deparamos aqui com precárias situações de pré-modemidade: famílias pobres mobilizadas para a sobrevivência instrumental diária, uma representação da criança como pequeno adulto, necessidade de recurso precoce ao trabalho infantil na rede de trabalho familiar (de onde muitas vezes os homens emigraram), predomínio de uma cultura de destituição escolar que dificulta, se não o acesso, pelo menos a progressão regular da criança no sistema de ensino (SEBASTIÃO: 1998;DETEFP: 1998; PINTO: 1998). Insucesso repetido, abandono escolar prematuro da escola são a outra face desta realidade, a qual choca frontalmente com a representação moderna da infância "educativa". O mesmo se poderá afirmar a respeito da relação destas famílias com o sistema de saúde: as crianças não fazem vigilância médica regular, muitas não possuem o boletim

A título ilustrativo, assinale-se que em 1996 (data da aplicação do inquérito) a taxa de actividade feminina (15-64 anos) em Portugal rondava os 42\%, sendo que esse indicador subia para os $80 \%$ se se considerassem apenas as mulheres entre os 25 e os 39 anos, em pleno ciclo de maternidade activa (ALMEIDA et. al: 1998). No Recenseamento de 2001, e se adoptarmos agora como ponto de referência as crianças (e não as mulheres), constata-se que apenas $18 \%$ delas possuem uma "mãe doméstica"; aliás, e confirmando tendências anteriores, quanto mais novas são as crianças, maior é a taxa de actividade materna: 69\% nas mães de bebés (0-2 anos) e nas de crianças entre os 3-5 anos, 63\% nas dos jovens entre 10-14 anos (ALMEIDA e ANDRÉ: 2004).

10 Estimava-se, em princípios da década de 90, que cerca de $1 / 4$ das famílias portuguesas vivia em situação de pobreza (BRUTO DA COSTA: 1992). Velhas ou novas formas de pobreza não têm aparentemente regredido desde então (CAPUCHA: 1998). 
de vacinas em dia. Com uma presença impressionante na amostra (lembremos que ronda os 50\%), o alcoolismo dos adultos responsáveis pela criança é outro indicador dramático destes contextos de vulnerabilidade e pobreza.

Quatro outros tipos de mau trato surgem com destaque em grupos sociais que já ocupam uma posição intermédia na pirâmide de lugares sociais: o "abuso sexual", a "agressão física com sequela", a "intoxicação" e o "mau trato in utero". No primeiro, aliás, estão sobrerrepresentadas as franjas de indivíduos sem habilitações ou, no máximo, com 6 anos de escolaridade; os activos empregados nos serviços pessoais ou domésticos, os empregados do comércio, os operários da construção civil ou da indústria, os pequenos comerciantes; as domésticas e os reformados sobressaem entre os inactivos. Os outros três tipos apontam para camadas ligeiramente mais favorecidas, sobretudo do ponto de vista escolar, com o predomínio de adultos responsáveis pela criança detentores de um diploma de ensino primário ou secundário. O "mau trato in utero", em particular, surge associado aos comportamentos de alcoolismo e toxicodependência.

Os grupos tendencialmente mais favorecidos salientam-se, pelo contrário, no tipo de "abuso emocional com agressão física", o qual pressupõe a violenta manipulação afectiva de emoções. A sua condição privilegiada (no contexto da amostra) é caracterizada pela residência em contextos de qualidade média, a posse de níveis superiores de instrução, o exercício de actividade em profissões como as de técnicos superiores e médios, empregados de comércio ou dos serviços pessoais e domésticos.

O contexto social em que insere a família da criança parece assim ter um impacto decisivo na definição da natureza e dimensões do mau trato de que ela é vítima. Se nas práticas de abuso típicas das classes populares prevalecem os gestos e o contacto físico entre os corpos, já a matéria-prima que constitui o mau trato praticado pelas classes dominantes parecem ser as palavras, as emoções e os afectos, as relações psicológicas entre adultos e crianças. A diversidade encontrada nestas práticas "extremas" não será, afinal, completamente estranha aos estilos e valores educativos entre pais e filhos, prevalecentes num ou noutro meio, de que aqueles parecem ser, de resto, uma ilustração pontual: imposição estatutária e coerciva da disciplina e autoridade, recurso a castigos físicos, por um lado; negociação partilhada de compromissos com a criança, estratégias de persuasão e influência, através do discurso, da palavra da gestão emocional, por outro (KELLERHALS, MONTANDON: 1991).

Para além da sua variação ser condicionada por clivagens sociais, os tipos de mau trato são igualmente sensíveis a clivagens de género. Raparigas e rapazes estão presentes na amostra, mas são vítimas típicas de diferentes modalidades de abuso ou negligência. As primeiras estão claramente sobrerrepresentadas 
nos casos de "abuso sexual" (onde os agressores reportados são, sem excepção, homens), nas de "ausência de guarda" em casa ou nas de "intoxicação intencional". Os rapazes destacam-se, por seu tumo, nas situações de "agressão" (física e emocional) e de "trabalho abusivo", nas grandes negligências de "cuidados básicos". No que constitui um prolongamento de estereótipos dominantes, deparamos com os tradicionais marcadores de género: a centralidade da casa e das relações de afecto nos maus tratos contra as raparigas, a relevância do trabalho e da força física nos rapazes. O mesmo sucede, curiosamente, do lado do universo dos agressores em matéria de "abuso sexual". Um resultado surpreendente do inquérito prende-se justamente com o facto de não terem sido denunciados quaisquer casos de agressores do sexo feminino. A invisibilidade social da sexualidade activa feminina, aqui associada à figura da mãe ou a outra familiar próxima da criança e, sobretudo, às suas formas mais perversas, é outro indicador do peso dos estereótipos na construção do olhar sobre o mau trato.

\section{Nota final}

Dando conta da diversidade dos contextos socio-familiares a que se associam estruturalmente os diferentes tipos de abuso e negligência contra a criança na família, mostrando como eles estão socialmente enraizados, como uns se imbricam nos outros e, desde logo, como a sua visibilidade e reconhecimento são fruto de um universo de valores dominantes sobre a infância, o estudo realizado por esta equipa, e aqui sumariamente apresentado, ilustra as potencialidades do contributo específico das ciências sociais para o diagnóstico e discussão do problema do mau trato infantil.

Num domínio tão complexo, sombrio e trágico como o do sofrimento da criança na sua família de origem, a investigação e a intervenção não podem dispensar o concurso de pistas de caracterização, interpretação e explicação provenientes de paradigmas científicos distintos. Porque nenhum deles detém o monopólio da verdade sobre as coisas - e só num compromisso exigente de fazer confluir pontos de vista diversos, mas complementares, se poderá avançar no campo da ciência e, consistentemente, no da prevenção.

\section{Bibliografia}

ALMEIDA, A. Nunes de, ANDRÉ, I. e ALMEIDA, H. Nunes de (2001)-Famílias e maus tratos às crianças em Portugal, Lisboa: Assembleia da República. ALMEIDA, A. Nunes de, ANDRÉ, I. e ALMEIDA, H. Nunes de (1999) - "Sombras e marcas: os maus tratos às crianças na família", Análise Social, (150). 
ALMEIDA, A. Nunes e ANDRÉ, I. M. (2004) - “O país e a família através das crianças - ensaio exploratório", Revista de Estudos Demográficos, (35).

ALMEIDA, A. Nunes de et. al. (1998) - “ Relações familiares: mudança e diversidade", in J. M. Leite Viegas e A. Firmino da Costa (eds.) - Portugal - que modernidade?. Oeiras: Celta.

AMARO, F. (1989) - "Aspectos socio-culturais dos maus tratos e negligência de crianças em Portugal”. Revista Portuguesa de Pediatria, (20).

ARIÈS, P. ( 1960) - L'enfant et la vie familiale sous l'Ancien Régime, Paris: Seuil.

BASTOS, A. ( 1999) - Pobreza infantil - ensaio de conceptualização e medição com a aplicação a uma zona urbana em Portugal (dissertação de doutoramento em Economia). Lisboa: ISEG.

BURGESS, E., LOCKE, J. e THOMAS, M. (1960) - Thefamily from institution to companionship, N.Iorque: American Book.

CANHA, J. (1997) - Criança maltratada. O papel de uma pessoa de referência na sua recuperação. Estudo prospectivo de 5 anos (dissertação de doutoramento em Medicina). Coimbra: Faculdade de Medicina.

CAPUCHA, L. M. A. (1998) - "Pobreza, exclusão social e marginalidades" in in J. M. Leite Viegas e A. Firmino da Costa (eds.) - Portugal-que modernidade?. Oeiras: Celta.

COSTA, A. Bruto da (1992) - The paradox of poverty. Portugal, 1980-1989. Bath: University of Bath

DETEFP (1998) - Inquérito à caracterização social dos agregados familiares com menores em idade escolar (trabalho infantil). Lisboa: Ministério do Trabalho e da Solidariedade.

DIAS, I. (2004) - Violência na família - uma abordagem sociológica. Porto: Afrontamento.

DURKHEIM, E. ( 1895,1977) - A Divisão Social do Trabalho I, Lisboa: Presença.

FOUCAULT, M. (1976) - La volonté de savoir, Paris: Gallimard.

FRISCH, P. et JOSEPH, I. (1977) - Disciplines à domicile, Paris: Recherches.

KELLERHALS, J. e MONTANDON, C. ( 1991 ) - Les stratégies éducatives des familles. Lausanne : Delachaux et Niestlé.

KELlERHALS, J., WIDMER, E., LEVY, R. (2004) - Mesure et demesure du couple. Paris: Payot.

KORBIN, J. (1987) «Child sexual abuse : implications from the cross-cultural record » in Nancy Scheper-Hughes (ed.) - Child survival. Dordrecht: Reidel Publishing Company.

HALLET, C. (1995) - «Child abuse : an academie overview» in P. Kingston e B. Penhale (eds.) - Family violence and the caring professions. London: Macmillan. 
MARTINS, P.C. (1998) - O conceito de maus-tratos a crianças - um estudo das noções dos profissionais da infância (dissertação de Mestrado em Psicologia), Porto: Faculdade de Psicologia e Ciências da Educação.

MINISTÉRIO DO TRABALHO E DA SOLIDARIEDADE (1998)- Inquérito à caracterização social dos agregados familiares com menores em idade escolar (trabalho infantil). Lisboa: Ministério do Trabalho e da Solidariedade.

PINTO, G. A. (1998) - O trabalho das crianças. De pequenino é que se torce o pepino (e o destino). Oeiras: Celta.

PINTO, M. (1997) - "A infância como construção social” in M. Pinto e M. Sarmento (eds.). As crianças - contextos e identidades. Braga: UM/CEC.

PORTUGAL, S. (2000) - "Globalização e violência doméstica". Revista Crítica de Ciências Sociais, (57/58).

RENAUT, A. (2004) - "L'enfant à l'épreuve de ses droits" in F. de Singly (dir.). Enfants et adultes. Vers une égalité de statuts?. Encyclopaedia Universalis France SA.

SARMENTO, M. e PINTO, M. (1997) - "As crianças e a infância: definindo conceitos, delimitando o campo" in M. Pinto e M. J. Sarmento (eds.). As crianças, contextos e identidades. Braga: UM/CEC.

SCHEPER-HUGHES, N. e STEIN, H.F. (1987) - "Child abuse ant the unconscious in American popular culture" in N. Scheper-Hughes (ed.) - Child survival. Dodrecht: D. Reidel Publishing Company.

SCHEPER-HUGHES, N. (1987) - (ed) "The cultural politics of child survival" Child survival. Dodrecht: D. Reidel Publishing Company.

SEBASTIÃO, J. (1998) - “Os dilemas da escolarização. Universalização, diversidade e inovação" in in J. M. Leite Viegas e A. Firmino da Costa (eds.) - Portugal - que modernidade?. Oeiras: Celta.

SOARES, N. F. (1998) - Outras infâncias... a situação social das crianças atendidas numa Comissão de Protecção de Menores (provas de aptidão pedagógica e capacidade científica), Braga: IEC/Universidade do Minho.

SHORTER, E. (1977) - Naissance de la famille moderne, Paris: Seuil.

SINGLY, F. (2000) - L'individualisme dans la vie commune. Paris: Nathan.

SINGLY, F. (2003) - Les uns avec les autres - quand l'individualisme crée du lien. Paris : A. Colin.

STONE, L. (1979) - The family, sex and marriage in England, 1500-1800, N. Iorque: Colophon Books.

STRAUSS, M., GELlES, R. e STEINMETZ, S. (1988) - Behind close doors violence in the American family, London: Sage Publications.

TORRES, A. e SILVA, F. V. (1998) - "Guarda das crianças e divisão do trabalho entre homens e mulheres”, Sociologia-Problemas e Práticas, (27). 
TORRES, A. (2001) - Sociologia do casamento. Oeiras: Celta.

WALL, K. e LOBO, C. (1999) - "Famílias monoparentais em Portugal", Análise Social, 34 (150). 